\title{
Evaluation of a-tubulin, detyrosinated a- tubulin, and vimentin in CTCs: identification of the interaction between CTCs and blood cells through cytoskeletal elements
}

\author{
G. Kallergi ${ }^{1,2^{*}}$ (D, D. Aggouraki ${ }^{1}$, N. Zacharopoulou ${ }^{2}$ C. Stournaras², V. Georgoulias ${ }^{1}$ and S. S. Martin ${ }^{3}$
}

\begin{abstract}
Background: Circulating tumor cells (CTCs) are the major players in the metastatic process. A potential mechanism of cell migration and invasion is the formation of microtentacles in tumor cells. These structures are supported by a-tubulin (TUB), detyrosinated a-tubulin (GLU), and vimentin (VIM). In the current study, we evaluated the expression of those cytoskeletal proteins in CTCS.

Methods: Forty patients with breast cancer (BC) (16 early and 24 metastatic) were enrolled in the study. CTCs were isolated using the ISET platform and stained with the following combinations of antibodies: pancytokeratin (CK)/NIM/ TUB and CKVIM/GLU. Samples were analyzed with the ARIOL platform and confocal laser scanning microscopy.

Results: Fluorescence quantification revealed that the ratios CKTUB, CKNIM, and CKVGLU were statistically increased in MCF7 compared with more aggressive cell lines (SKBR3 and MDA-MB-231). In addition, all of these ratios were statistically increased in MCF7 cells compared with metastatic BC patients' CTCs ( $p=0.0001, p=0.0001$, and $p=0.003$, respectively). Interestingly, intercellular connections among $C T C s$ and between $C T C s$ and blood cells through cytoskeleton bridges were revealed, whereas microtentacles were increased in patients with CTC clusters. These intercellular connections were supported by TUB, VIM, and GLU. Quantification of the examined molecules revealed that the median intensity of TUB, GLU, and VIM was significantly increased in patients with metastatic BC compared with those with early disease (TUB, 62.27 vs $11.5, p=0.0001 ; \mathrm{GLU}, 6.99$ vs $5.29, p=0.029$; and VIM, 8.24 vs $5.38, p=0.0001$, respectively).

Conclusions: $C T C$ from patients with BC aggregate to each other and to blood cells through cytoskeletal protrusions, supported by VIM, TUB, and GLU. Quantification of these molecules could potentially identify CTCs related to more aggressive disease.
\end{abstract}

Keywords: CTCS, Microtentacles, a-Tubulin, Detyrosinated a-tubulin, Vimentin, Breast cancer, Cytoskeleton, Metastasis

\section{Background}

Metastasis, rather than the primary tumor, is mainly responsible for cancer-related death. The metastatic process is associated with the presence of circulating tumor cells (CTCs) and disseminated tumor cells in peripheral blood and bone marrow, respectively $[1,2]$. CTCs hold stem and epithelial-to-mesenchymal transition (EMT) properties,

\footnotetext{
* Correspondence: kalergi@med.uoc.gr

'Laboratory of Tumor Cell Biology, School of Medicine, University of Crete, Heraklion, Greece

${ }^{2}$ Department of Biochemistry, University of Crete, Greece Medical School, Heraklion, Greece

Full list of author information is available at the end of the article
}

which are difficult to target with common chemotherapeutic agents [3-5]. The malignant nature of CTCs is supported by the presence of chromosomal alterations and by xenograft mouse models [6-9]. However, some of them are dormant or apoptotic $[10,11]$, and it seems that only a small proportion of CTCs are capable of forming overt tumor deposits [12].

CTCs are an extremely heterogeneous population; therefore, it is crucial to isolate and effectively characterize CTCs according to their tumorigenic capacity [12]. We have reported that CTCs express growth factor receptors and activated signaling kinases such as epidermal growth 
factor receptor, human epidermal growth factor receptor 2 (HER2), phosphorylated phosphatidylinositol 3-kinase, p-AKT, and p-FAK $[13,14]$. However, it has been shown that there are important phenotypic and biological discrepancies between CTCs and patients' primary tumors, implying that it is crucial to characterize these cells and use them as potential targets for cancer treatment $[13,15-17]$. To this end, we have reported that it is possible to improve patients' outcomes by targeting CTCs rather than primary tumors and prevent tumor cell spreading [18].

A mechanism for metastatic dissemination is the formation of microtentacles. These cytoskeletal structures are supported by $\alpha$-tubulin (TUB) and associated with the EMT pathways $[19,20]$. Vimentin (VIM), Twist, and Snail are particularly upregulated in microtentacle-expressing cells. Furthermore, cancer cells with the capacity for cell migration and invasion are characterized by stem cell phenotype and microtentacle protrusions [19-24]. Detyrosinated $\alpha$-tubulin (GLU) is another interesting characteristic of these cytoskeletal structures, considering the fact that GLU is a poor prognostic factor for patients with positive primary tumors [25].

Recent evidence indicates that common chemotherapeutic agents such as taxanes cause shedding of CTCs into the bloodstream, which can dramatically increase cancer spread and relapse $[26,27]$. Taxanes can also increase microtentacles, promoting tumor cell reattachment [28]. However, other drugs such as kinesin inhibitors or curcumin can diminish microtentacles and inhibit tumor cell dissemination [22, 29].

The characterization of the microtentacles' structural proteins in isolated CTCs from patients with breast cancer (BC) has not been extensively addressed so far. The goal of the current study was to identify these molecules on isolated CTCs and to explore their potential interference with the metastatic process. Finally, we investigated possible implications of microtentacles in inter-CTC communication and in CTC-to-blood cell crosstalk.

\section{Methods}

\section{Cell cultures}

Three different BC cell lines, representative of distinct subtypes, were used to create an expression pattern of the assessed molecules: MCF7 (hormone receptor-positive $\left.\left[\mathrm{HR}^{+}\right]\right)$, SKBR3 $\left(\mathrm{HER}^{+}\right)$, and MDA-MB-231 (basal-like). All cell lines were obtained from the American Type Culture Collection (Manassas, VA, USA). The MCF7 cells were cultured in 1:1 (vol/vol) DMEM/Ham's F-12 medium (Life Technologies, Carlsbad, CA, USA) supplemented with $10 \%$ FBS (Life Technologies), $2 \mathrm{mM}$ L-glutamine (Life Technologies) $30 \mathrm{mM} \mathrm{NaHCOB} 3 \mathrm{~B}, 16 \mathrm{ng} / \mathrm{ml}$ insulin, and $50 \mathrm{mg} / \mathrm{ml}$ penicillin/streptomycin (Life Technologies). SKBR3 cells were cultured in McCoy's medium (Life Technologies) enriched with 10\% FBS and $2 \mathrm{mM}$ L-glutamine supplemented with $50 \mathrm{mg} / \mathrm{ml}$ penicillin/streptomycin. MDA-MB-231 cells were cultured in high-glucose DMEM (Life Technologies) with 10\% FBS and $2 \mathrm{mM}$ L-glutamine supplemented with $50 \mathrm{mg} / \mathrm{ml}$ penicillin/streptomycin. Cells were maintained in a humidified atmosphere of $5 \%$ $\mathrm{CO}_{2} / 95 \%$ air. Subcultivation for all cell lines was performed with $0.25 \%$ trypsin and $5 \mathrm{mM}$ ethylenediaminetetraacetic acid (EDTA). All experiments were performed during the logarithmic growth phase. For spiking experiments, various dilutions $(10 \mathrm{cells} / \mathrm{ml}, 100 \mathrm{cells} / \mathrm{ml}$, and 1000 cells $/ \mathrm{ml}$ of blood) of cells from three cell lines were spiked in $10 \mathrm{ml}$ of blood obtained from healthy blood volunteers.

\section{Patients' blood samples}

Peripheral blood (10 ml in EDTA) was obtained from 16 chemotherapy-naïve patients with early $\mathrm{BC}$ and 24 patients with metastatic disease, before the initiation of any line of treatment, according to the design of a previous study [30]. Patients without evidence of metastatic disease (stages I-II) were considered to have early BC, whereas patients with stage IV disease were included in the metastatic group. Most of the patients were postmenopausal (62.5\% early and $58.3 \%$ metastatic) in both cohorts. The $\mathrm{HR}^{+}$type comprised $75 \%$ of adjuvant and $62.5 \%$ of metastatic subjects. Triple-negative tumors $\left(\mathrm{HR}^{-} \mathrm{HER} 2^{-}\right)$were represented in $6.3 \%$ of the patients with early disease and in $25 \%$ with metastatic disease. Sixteen patients from the metastatic group were initially diagnosed with early and operable disease, and seven other patients were diagnosed with metastatic disease from the beginning of the study. All the patients' characteristics are shown in Table 1.

Blood samples were collected at the middle of vein puncture after the first $5 \mathrm{ml}$ of blood were discarded in order to avoid contamination of the blood sample with epithelial cells from the skin during sample collection. This protocol was approved by the ethics and scientific committees of our institution, and all patients and healthy blood donors gave their informed consent to participate in the study.

\section{ISET system isolation of circulating tumor cells}

CTCs were isolated using the ISET (Isolation by SizE of Tumor cells) platform (Rarecells Diagnostics, Paris, France) according to the manufacturer's instructions. This isolation system was chosen because in a previous study it was shown that the ISET platform has a high recovery rate of tumor cells, regardless of the $\mathrm{BC}$ subtype [31]. Briefly, $10 \mathrm{ml}$ of peripheral blood were diluted in 1:10 ISET buffer (Rarecells Diagnostics) for $10 \mathrm{~min}$ at room temperature (RT), and $100 \mathrm{ml}$ of the diluted sample was filtered using a depression tab adjusted at $-10 \mathrm{kPa}$. The membrane was dried for $2 \mathrm{~h}$ at $\mathrm{RT}$ and 
Table 1 Patients' characteristics

\begin{tabular}{|c|c|c|c|}
\hline \multicolumn{2}{|l|}{ Early disease (16 patients) } & \multicolumn{2}{|c|}{ Metastatic disease (24 patients) } \\
\hline \multirow[t]{2}{*}{ Age, yr, median (range) } & $53(33-77)$ & Age, yr, median (range) & $58(39-70)$ \\
\hline & No. (\%) & & №. (\%) \\
\hline \multicolumn{2}{|l|}{ Menopausal status } & \multicolumn{2}{|l|}{ Menopausal status } \\
\hline Premenopausal & $4(25 \%)$ & Premenopausal & $7(29.2 \%)$ \\
\hline Postmenopausal & $10(62.5 \%)$ & Postmenopausal & $14(58.3 \%)$ \\
\hline Unknown & $2(12.5 \%)$ & Unknown & $3(12.5 \%)$ \\
\hline \multicolumn{2}{|l|}{ Tumor size } & \multicolumn{2}{|l|}{ Tumor size } \\
\hline pT1 & $9(56.3 \%)$ & pT1 & $4(16.7 \%)$ \\
\hline pT2 & $5(31.3 \%)$ & pT2 & $12(50 \%)$ \\
\hline pT3 & $0(0 \%)$ & pT3 & $4(16.7 \%)$ \\
\hline Unknown & $2(12.5 \%)$ & Unknown & $4(16.7 \%)$ \\
\hline \multicolumn{2}{|l|}{ Lymph node status } & \multicolumn{2}{|l|}{ Lymph node status } \\
\hline Node-negative & $4(25 \%)$ & Node-negative & $9(37.5 \%)$ \\
\hline Node-positive & $11(68.8 \%)$ & Node-positive & $10(41.7 \%)$ \\
\hline Unknown & $1(6.3 \%)$ & Unknown & $5(20.8 \%)$ \\
\hline \multicolumn{2}{|l|}{ Histologic grade } & \multicolumn{2}{|l|}{ Histologic grade } \\
\hline Grade 1 & $0(0 \%)$ & Grade 1 & $0(0 \%)$ \\
\hline Grade 2 & $10(62.5 \%)$ & Grade 2 & $12(50 \%)$ \\
\hline Grade 3 & $3(18.8 \%)$ & Grade 3 & $9(37.5 \%)$ \\
\hline Grade 4 & & Grade 4 & $3(12.5 \%)$ \\
\hline Unknown & $3(18.8 \%)$ & Unknown & $0(0 \%)$ \\
\hline \multicolumn{2}{|l|}{ Histologic subtype } & \multicolumn{2}{|l|}{ Histologic subtype } \\
\hline Ductal & $12(75 \%)$ & Ductal & $17(70.8)$ \\
\hline Lobular & $1(6.3 \%)$ & Lobular & $2(8.3 \%)$ \\
\hline Other & $3(18.8 \%)$ & Other & $5(20.8 \%)$ \\
\hline \multicolumn{2}{|l|}{ ER/PR tumor status } & \multicolumn{2}{|l|}{ ER/PR tumor status } \\
\hline Positive & $12(75 \%)$ & Positive & $15(62.5 \%)$ \\
\hline Negative & $2(12.5 \%)$ & Negative & $6(25 \%)$ \\
\hline Unknown & $2(12.5 \%)$ & Unknown & $3(12.5 \%)$ \\
\hline \multicolumn{2}{|l|}{ HER2 tumor status } & \multicolumn{2}{|l|}{ HER2 tumor status } \\
\hline Positive $^{a}$ & $7(43.8 \%)$ & Positive $^{a}$ & $3(12.5 \%)$ \\
\hline Negative & $6(37.5 \%)$ & Negative & $18(75 \%)$ \\
\hline Unknown & $3(18.8 \%)$ & Unknown & $3(12.5 \%)$ \\
\hline $\mathrm{HR}^{+} / \mathrm{HER} 2^{-}$ & $5(31.3 \%)$ & $\mathrm{HR}^{+} / \mathrm{HER}^{-}$ & $12(50 \%)$ \\
\hline $\mathrm{HR}^{+} / \mathrm{HER} 2^{+}$ & $6(37.5 \%)$ & $\mathrm{HR}^{+} / \mathrm{HER}^{+}$ & $3(12.5 \%)$ \\
\hline $\mathrm{HR}^{-} / \mathrm{HER} 2^{+}$ & 1 (6.3\%) & $\mathrm{HR}^{-} / \mathrm{HER} 2+$ & $0(0 \%)$ \\
\hline $\mathrm{HR}^{-} / \mathrm{HER}^{-}$ & $1(6.3 \%)$ & $\mathrm{HR}^{-} / \mathrm{HER} 2^{-}$ & $6(25 \%)$ \\
\hline \multirow[t]{6}{*}{ Unknown combination } & $3(18.8 \%)$ & Unknown combination & $3(12.5 \%)$ \\
\hline & & \multicolumn{2}{|l|}{ Disease sites } \\
\hline & & 1 & $8(33.3 \%)$ \\
\hline & & 2 & $11(45.8 \%)$ \\
\hline & & $\geq 3$ & $4(16.6 \%)$ \\
\hline & & Unknown & $1(4.2 \%)$ \\
\hline
\end{tabular}

Predominantly visceral disease 
Table 1 Patients' characteristics (Continued)

\begin{tabular}{|c|c|c|}
\hline \multirow[t]{2}{*}{ Early disease (16 patients) } & \multicolumn{2}{|c|}{ Metastatic disease (24 patients) } \\
\hline & Yes & $15(62.5 \%)$ \\
\hline & No & $7(29.1 \%)$ \\
\hline & Unknown & $2(8.3 \%)$ \\
\hline & \multicolumn{2}{|c|}{ Primary breast cancer } \\
\hline & Adjuvant & $16(66.7 \%)$ \\
\hline & Metastatic & $7(29.2 \%)$ \\
\hline & Unknown & $1(4.2 \%)$ \\
\hline & \multicolumn{2}{|l|}{ Line of treatment } \\
\hline & First & $8(33.3 \%)$ \\
\hline & Second & $8(33.3 \%)$ \\
\hline & Third & $3(12.5 \%)$ \\
\hline & Fourth or later & $5(20.8 \%)$ \\
\hline
\end{tabular}

Abbreviations: ER Estrogen receptor, $P R$ Progesterone receptor, $H R$ Hormone receptor, HER2 Human epidermal growth factor receptor 2

apositive were considered all the patients with HER2 score +3 in immunohistochemistry staining or +2 with positive FISH

stored at $-20{ }^{\circ} \mathrm{C}$. Each membrane spot was used for identification of CTCs after immunostaining and fluorescence microscopy analysis.

\section{Confocal laser scanning and Ariol system microscopy}

The presence of CTCs on ISET spots was evaluated using A45-B/B3 mouse antibody (Micromet, Munich, Germany) detecting CK8, CK18, and CK19, along with CD45 antibody (common leukocyte antigen), in order to exclude possible ectopic expression of cytokeratins by hematopoietic cells. A patient was considered as CTC-positive only if she harvested $\mathrm{CK}^{+} / \mathrm{CD} 45^{-}$cells (Fig. 2d). In addition, the cytomorphological criteria followed by Meng et al. were also used in order to characterize a cell as CTCs [9].

Consequently, patients were analyzed for the expression of TUB, GLU, and VIM. Triple-staining experiments were performed with the following combinations of antibodies: CK/TUB/VIM and CK/GLU/VIM. The samples were subsequently evaluated using the Ariol system (Leica Biosystems, Buffalo Grove, IL, USA) and confocal laser scanning microscopy.

For CK/TUB/VIM immunofluorescence staining, spots were incubated with PBS for $5 \mathrm{~min}$, and then cells were permeabilized with $2 \%$ Triton X-100 for 10 min. After $1 \mathrm{~h}$ blocking with PBS/10\% FBS, cells were incubated with VIM antirabbit antibody (Santa Cruz Biotechnology, Santa Cruz, CA, USA), followed by Alexa Fluor 633 antirabbit secondary antibody (Life Technologies). Subsequently, samples were stained with TUB antimouse antibody (Sigma-Aldrich, Taufkirchen, Germany) and Alexa Fluor 555 antimouse secondary antibody (Life Technologies) for 45 min Zenon technology (fluorescein isothiocyanate-conjugated immunoglobulin G1 [IgG1] antibody; Molecular Probes, Eugene, OR, USA) was used for CK detection with the A45-B/B3 antibody. Zenon antibodies were prepared within $30 \mathrm{~min}$ before use [16].

For triple-staining of CK/GLU/VIM, the same blocking and permeabilization procedures were followed, and the membranes were incubated with A45-B/B3 mouse antibody for $1 \mathrm{~h}$. Consequently, after incubation for $45 \mathrm{~min}$ with the secondary antibody (Alexa Fluor 488 antimouse; Life Technologies), cells were stained with GLU antirabbit antibody (Abcam, Cambridge, MA, USA) overnight. Subsequently, cells were incubated with Alexa Fluor 633 antirabbit antibody. Finally, Zenon technology (Alexa Fluor 555-conjugated IgG1 antibody) was used for VIM staining (Santa Cruz Biotechnology). Positive controls were also included in each experiment, using the aforementioned cell lines spiked in healthy volunteers' blood, whereas negative controls were prepared by omitting the corresponding primary antibodies and incubating the cells with the matching IgG isotype bound to the corresponding fluorochrome. Each patient with at least one CTC belonging to a distinct phenotype was considered as positive for this phenotype.

\section{Statistical analysis}

The criteria for the evaluation of objective response rate (ORR) were according to RECIST 1.1 (Response Evaluation Criteria In Solid Tumors): tumor size, lymph node status, lesion number, and so forth [32]. Overall survival (OS) was defined as the time from entrance into the study until death from any cause. Progression-free survival (PFS) was defined as extending from study 
enrollment until disease relapse or death, whichever occurred first. Kaplan-Meier curves and Cox regression analysis for PFS and OS were compared using the log-rank test to provide a univariate assessment of the prognostic value of selected clinical risk factors. Variables that were found to be significant in univariate analysis were then entered in a stepwise multivariate Cox proportional hazards regression model to identify those with independent prognostic value. All statistical tests were performed at the 5\% level of significance. IBM SPSS Statistics version 22 software (IBM, Armonk, NY, USA) was used for the analysis.

\section{Results}

\section{Evaluation of TUB, GLU, and VIM in BC cell lines}

The expression of TUB, GLU, and VIM in MCF7, SKBR3, and MDA-MB-231 cell lines was initially assessed with spiking experiments followed by ISET system isolation. Triple-staining experiments revealed that the ratios CK/TUB, CK/GLU, and CK/VIM were significantly increased in the well-differentiated $\mathrm{HR}^{+}$MCF7 cells compared with the more aggressive cell lines, such as SKBR3 and MDA-MB-231 (Table 2).

TUB intensity did not differ significantly among the cell lines. The highest GLU expression was observed in SKBR3 cells, where it was significantly different from MCF7 and MDA-MB-231 cells. VIM was extremely high in MDA-MB-231 cells compared with MCF7 and SKBR3 cells.

Microtentacles were observed mainly in MDA-MB-231 cells. We also noticed that coincubation of cancer cells with blood samples resulted in the appearance of cytoskeletal bridges between cancer and blood cells. This communication was observed mainly in SKBR3 and MDA-MB-231 spiked samples (Additional file 1: Figure S1).

\section{Evaluation of TUB and CK/TUB ratio in CTCs isolated from patients with early and metastatic $B C$}

CTCs were detected in 11 of 16 (68.8\%) and 16 of 24 (66.7\%) patients with early and metastatic BC, respectively. The mean and median numbers of CTCs per patient were 4.6 and 1 (range, 0-37), respectively, for early BC, whereas in metastatic subjects, the corresponding numbers were 59.5 and 1.5 (range, 0-1062). Triple-staining experiments (TUB/VIM/CK) and confocal laser scanning analysis revealed that CTCs contacted each other through cytoskeletal bridges (Fig. 1a-d, white arrows). In addition, they communicated with microtentacle connections with nearby blood cells. These inter-CTC bridges supported by TUB, VIM, and cytokeratin (Fig. 1a-d). However, microtentacles that connected CTCs to blood cells (Fig. 1e-h, white arrows) were mostly supported by TUB and VIM. Each patient with at least one $\mathrm{TUB}^{+} \mathrm{VIM}^{+} \mathrm{CK}^{+}$cell is considered as positive for this phenotype.

Ariol system analysis revealed that the phenotype $\left(\mathrm{TUB}^{+} \mathrm{VIM}^{+} \mathrm{CK}^{+}\right.$) prevailed in CTCs from patients with metastatic disease (8 of $16 \mathrm{CK}^{+}$patients; $50 \%$ ) compared with patients with early disease $\left(2\right.$ of $11 \mathrm{CK}^{+}$patients; $18.2 \%)(p=0.058)$ (Fig. 2a). Conversely, the incidence of the $\mathrm{TUB}^{+} \mathrm{VIM}^{-} \mathrm{CK}^{+}$phenotype was not changed between the two groups $(18.75 \%$ and $18.2 \%$, respectively). The

Table 2 Expression of a-tubulin, detyrosinated a-tubulin, and vimentin in cell lines and circulating tumor cells

\begin{tabular}{|c|c|c|c|c|c|c|}
\hline & Ratio CK/TUB & Tubulin & Ratio CK/GLU & GLU & Ratio CKNIM & Vimentin \\
\hline MCF7 & $5.46 \pm 0.7$ & $30.8 \pm 3.5$ & $20.41 \pm 0.6$ & $9.08 \pm 0.3$ & $42.22 \pm 2.8$ & $4.27 \pm 0.5$ \\
\hline SKBR3 & $1.49 \pm 0.7$ & $29.37 \pm 6.6$ & $12.49 \pm 0.9$ & $12.89 \pm 0.7$ & $31.34 \pm 2.4$ & $4.94 \pm 0.4$ \\
\hline MDA-MB 231 & $3.09 \pm 0.4$ & $26.19 \pm 3.1$ & $11.225 \pm 0.7$ & $8.045 \pm 0.2$ & $3.46 \pm 0.8$ & $28.87 \pm 3.7$ \\
\hline CTCs in patients with early breast cancer & $4.58 \pm 0.4$ & $11.50 \pm 0.4$ & $15.5 \pm 0.6$ & $5.29 \pm 0.6$ & $14.33 \pm 0.6$ & $5.38 \pm 0.3$ \\
\hline CTCs in patients with metastatic breast cancer & $1.75 \pm 0.4$ & $62.27 \pm 18.7$ & $15.28 \pm 2.8$ & $6.99 \pm 0.4$ & $8.05 \pm 1.9$ & $8.24 \pm 1$ \\
\hline$t$ tests & $p$ values & & & & & \\
\hline MCF7 vs MD-MB231 & 0.002 & 0.307 & 0.0001 & 0.0001 & 0.002 & 0.001 \\
\hline MCF7 vs SKBR3 & 0.0001 & 0.463 & 0.0001 & 0.005 & 0.011 & 0.235 \\
\hline MCF7 vs CTCs early & 0.038 & 0.0001 & 0.185 & 0.0001 & 0.002 & 0.022 \\
\hline MCF7 vs CTCs metastatic & 0.0001 & 0.0001 & 0.0001 & 0.0001 & 0.003 & 0.000 \\
\hline MDA-MB231 vs SKBR3 & 0.032 & 0.344 & 0.446 & 0.001 & 0.0001 & 0.0001 \\
\hline MDA-MB231 vs CTCs early & 0.332 & 0.0001 & 0.001 & 0.0001 & 0.0001 & 0.0001 \\
\hline MDA-MB231 vs CTCs metastatic & 0.0001 & 0.0001 & 0.000 & 0.124 & 0.000 & 0.0001 \\
\hline SKBR3 vs CTCs early & 0.036 & 0.010 & 0.001 & 0.0001 & 0.001 & 0.429 \\
\hline SKBR3 vs CTCs metastatic & 0.282 & 0.0001 & 0.002 & 0.0001 & 0.0001 & 0.0001 \\
\hline CTCs early vs CTCs metastatic & 0.0001 & 0.0001 & 0.937 & 0.029 & 0.007 & 0.0001 \\
\hline
\end{tabular}

Abbreviations: CK Cytokeratin, TUB a-Tubulin, GLU Detyrosinated a-tubulin, VIM Vimentin, CTCs Circulating tumor cells 

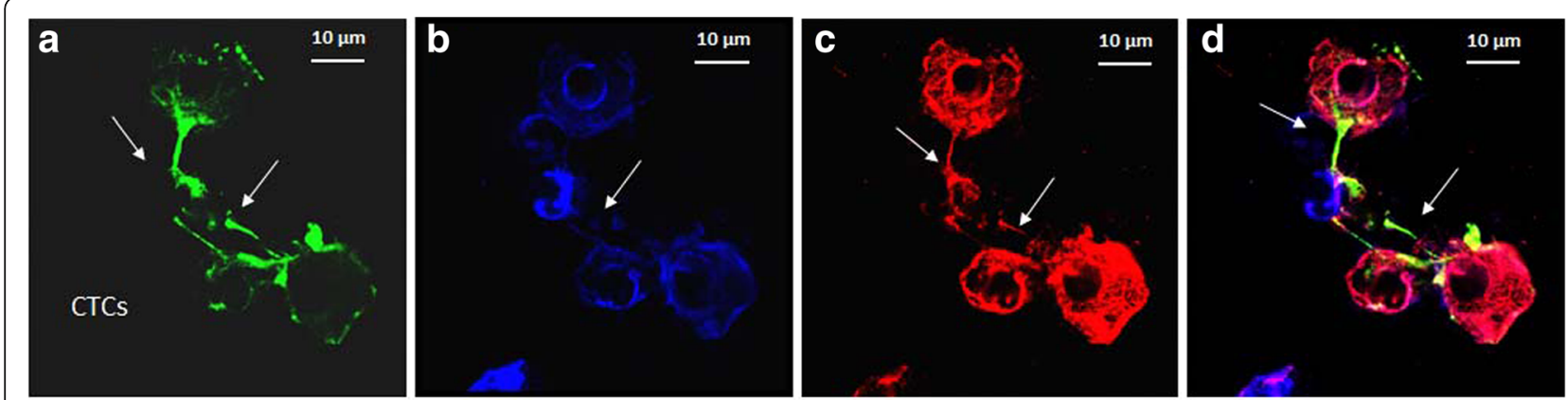

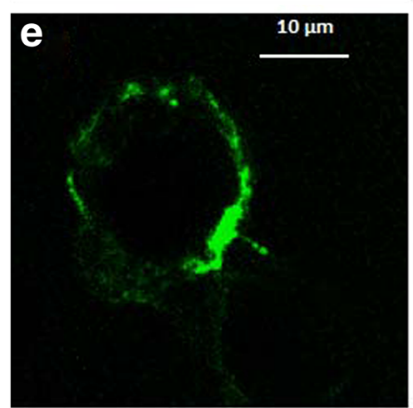

CK

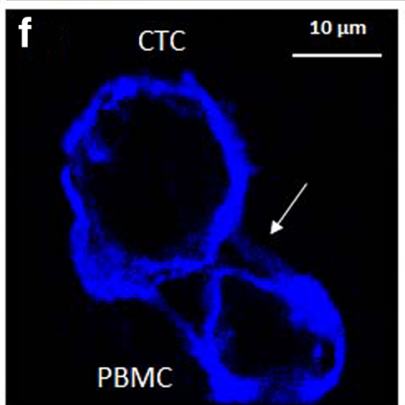

Vimentin

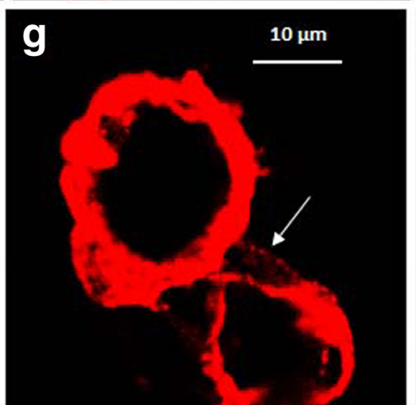

alpha-Tubulin

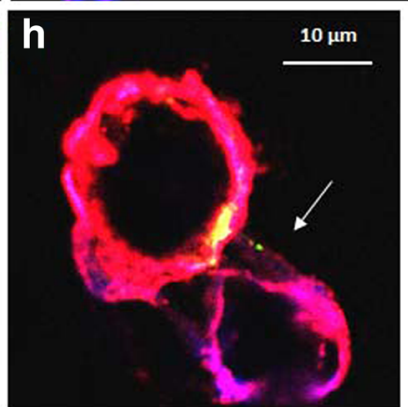

Overalay

Fig. 1 Expression of cytokeratin (CK), vimentin (VIM), and a-tubulin (TUB) in patients' CTCs. Patients' samples were stained with pancytokeratin (A45-B/B3) (green), vimentin (blue), a-tubulin antibodies (red), and 4',6-diamidino-2-phenylindole (DAPI) (not shown). a-d Representative confocal laser scanning micrographs of patients' CTCs $(\times 40)$. White arrow indicates the cytoskeleton bridges between CTCs supported by TUB, VIM, and CK. e-h Intercellular connections (white arrows) between a patient CTC and a blood cell (×60). CTCs were positively stained for CK (green), TUB (red), and VIM (blue), whereas blood cells are positive for VIM and TUB

absolute number of CTCs per patient for each distinct phenotype is shown in Table 3.

Quantification of TUB expression revealed statistically increased intensity in CTCs derived from patients with metastatic $\mathrm{BC}$ compared with all the examined cell lines (Table 2). Moreover, the intensity of TUB was statistically $(p=0.0001)$ lower in CTCs from patients with early BC $(11.5 \pm 0.4)$ compared with that observed in patients with metastatic disease $(62.27 \pm 18.7)$ (Table 2, Fig. 2b). Furthermore, the ratio CK/TUB was statistically lower $(p=0.0001)$ in metastatic patients' samples $(1.75 \pm 0.4)$ compared with the MCF7 $(5.46 \pm 0.7)$ and MDA-MB-231 $(3.09 \pm 0.4)$ cell lines (Table 2$)$.

The ratio of CK/TUB was significantly higher in CTCs detected in patients with early $\mathrm{BC}$ compared with that observed in CTCs from patients with metastatic disease ( $4.58 \pm 0.4$ vs $1.75 \pm 0.4 ; p=0.0001$ ) (Table 2; Fig. 2 c).

The distribution of all the CTCs regarding TUB intensity and CK/TUB ratio in both groups compared with MCF7, SKBR3, and MDA-MB-231 is shown in Additional files 2 and 3: Figures S2a, b and S3a, b, respectively.

Evaluation of GLU and CK/GLU ratio in patients with early and metastatic BC

Our results revealed that GLU participates in intercellular connections among patients' CTCs (Fig. 3).
GLU was expressed in a high percentages of patients with early and metastatic $\mathrm{BC}$. The $\mathrm{GLU}^{+} \mathrm{VIM}^{+} \mathrm{CK}^{+}$ phenotype could be identified in $54.5 \%$ (6 of 11) of patients with early $\mathrm{BC}$ and in $62.5 \%$ of patients with metastatic disease (10 of 16) (Fig. 2a). In addition, $\mathrm{GLU}^{+}$VIM $^{-} \mathrm{CK}^{+}$) CTCs could be detected in both patients with early BC (2 of 11 patients; $18.2 \%$ ) and patients with metastatic disease (6 of 16 patients; $37.5 \%)(p=0.69)$. Conversely, the phenotypes without GLU expression prevailed in an adjuvant setting compared with metastatic $\mathrm{BC}\left(\mathrm{GLU}^{-} \mathrm{VIM}^{+} \mathrm{CK}^{+}\right)$ (27.3\% [3 of 11] vs $13 \%$ [ 2 of $16 ; p=0.357)$. In addition, the $\mathrm{GLU}^{-} \mathrm{VIM}^{-} \mathrm{CK}^{+}$phenotype was detected in $36.36 \%$ ( 4 of 11 ) of patients with early $\mathrm{BC}$ and in $13.33 \%$ (2 of 16$)$ with metastatic disease $(p=0.357)$ (Fig. 2a).

The ratio CK/GLU was significantly higher in MCF7 cells $(20.41 \pm 0.6 ; p=0.0001)$ than in CTCs from patients with metastatic BC $(15.28 \pm 2.8)$ (Table 2). Median intensity of GLU per patient was significantly increased in patients with metastatic BC compared with patients with early disease $(5.29 \pm 0.6$ in early vs $6.99 \pm 0.4$ in metastatic setting; $p=0.029$ ) (Fig. $2 b$ ); however, the ratio of CK/GLU (Fig. 2c) did not reach statistical significance $(15.5 \pm 0.6$ vs $15.28 \pm 2.8 ; p=0.937)$. The distribution of all the CTCs regarding GLU intensity and CK/GLU 


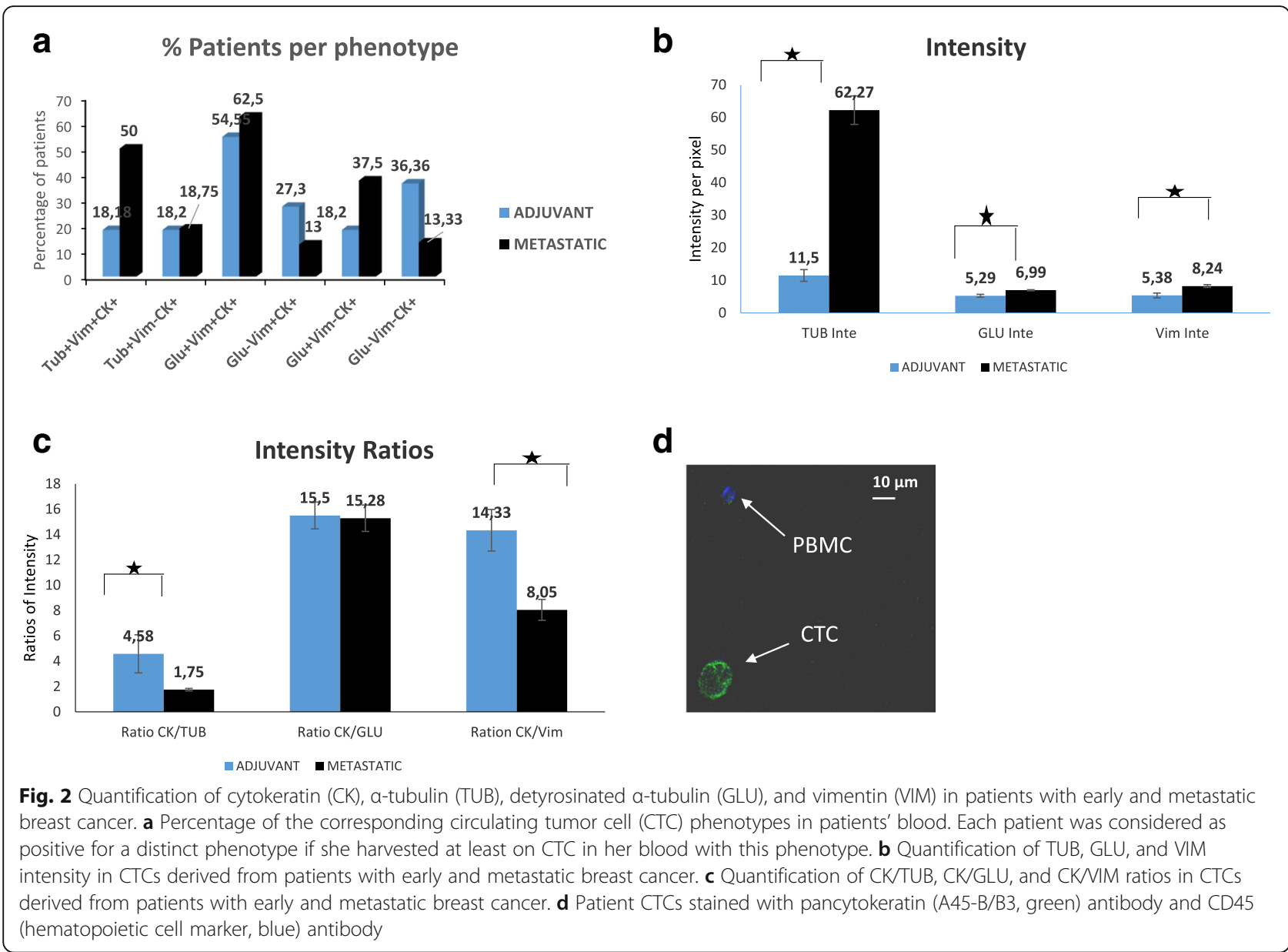

ratio is shown in Additional files 2 and 3: Figures S2c, d and S3c, d.

\section{Evaluation of VIM and CK/VIM ratio in patients with early and metastatic BC}

The intensity of VIM in CTCs detected in patients with metastatic $\mathrm{BC}(8.24 \pm 1)$ was statistically higher than in MCF7 (4.27 $\pm 0.5 ; p=0.0001)$ and SKBR3 (4.94 \pm 0.4 ; $p=0.0001$ ) cells (Table 2$)$. In addition, the intensity of VIM in patients with early $(5.38 \pm 0.3 ; p=0.022)$ and metastatic disease $(8.24 \pm 1 ; p=0.0001)$ was also significantly higher than in MCF7 cells (Table 2). Mann-Whitney analysis also revealed significantly increased VIM expression in CTCs from patients with metastatic BC $(8.24 \pm 1)$ compared with early disease $(5.38 \pm 0.3)(p=0.0001)$ (Fig. 2b).

CK/VIM ratio was lower in CTCs, regardless of disease stage, than in MCF7 cells (Table 2). In addition, the CK/VIM ratio was significantly lower (Fig. 2c) in patients with metastatic $\mathrm{BC}(8.05 \pm 1.9)$ than in those with early disease $(14.33 \pm 0.6, p=0.007)$.

There was also a positive correlation between the CK/ TUB and CK/GLU ratios in CTCs (Spearman's correlation analysis; $p=0.011)$. In addition, there was a positive correlation between $\mathrm{CTC}$ phenotypes $\mathrm{TUB}^{+} \mathrm{VIM}^{+} \mathrm{CK}^{+}$and $\mathrm{GLU}^{+} \mathrm{VIM}^{+} \mathrm{CK}^{+}(p=0.001)$ in patients with metastatic BC. Moreover, as shown in Table 3, only one patient with metastatic $\mathrm{BC}$ and one in the early $\mathrm{BC}$ group harvested both $\mathrm{GLU}^{+} \mathrm{VIM}^{+} \mathrm{CK}^{+}$and $\mathrm{GLU}^{-} \mathrm{VIM}^{+} \mathrm{CK}^{+} \mathrm{CTC}$ in their blood. Conversely, in the rest of the patients, all the CTCs were either positive or negative for these phenotypes. The distribution of all the CTCs regarding VIM intensity and CK/VIM ratio identified in both settings is shown in Additional file 2: Figure S2e and f and Figure S4e and f).

\section{Evaluation of TUB, GLU, and VIM in sequential samples from a patient with $B C$}

During this study, one patient with early $\mathrm{BC}$ relapsed and developed metastatic disease. Therefore, it was possible to analyze two different blood draws during the course of the disease. The first blood sample was obtained before any clinical or imaging evidence of relapse, whereas the second corresponded to the time of documentation of metastatic disease. In accordance with our previous observations, TUB's intensity in CTCs was statistically increased in the metastatic sample $(p=0.002)$ 
Kallergi et al. Breast Cancer Research (2018) 20:67

Page 8 of 13

Table 3 Number of circulating tumor cells per phenotype in each patient

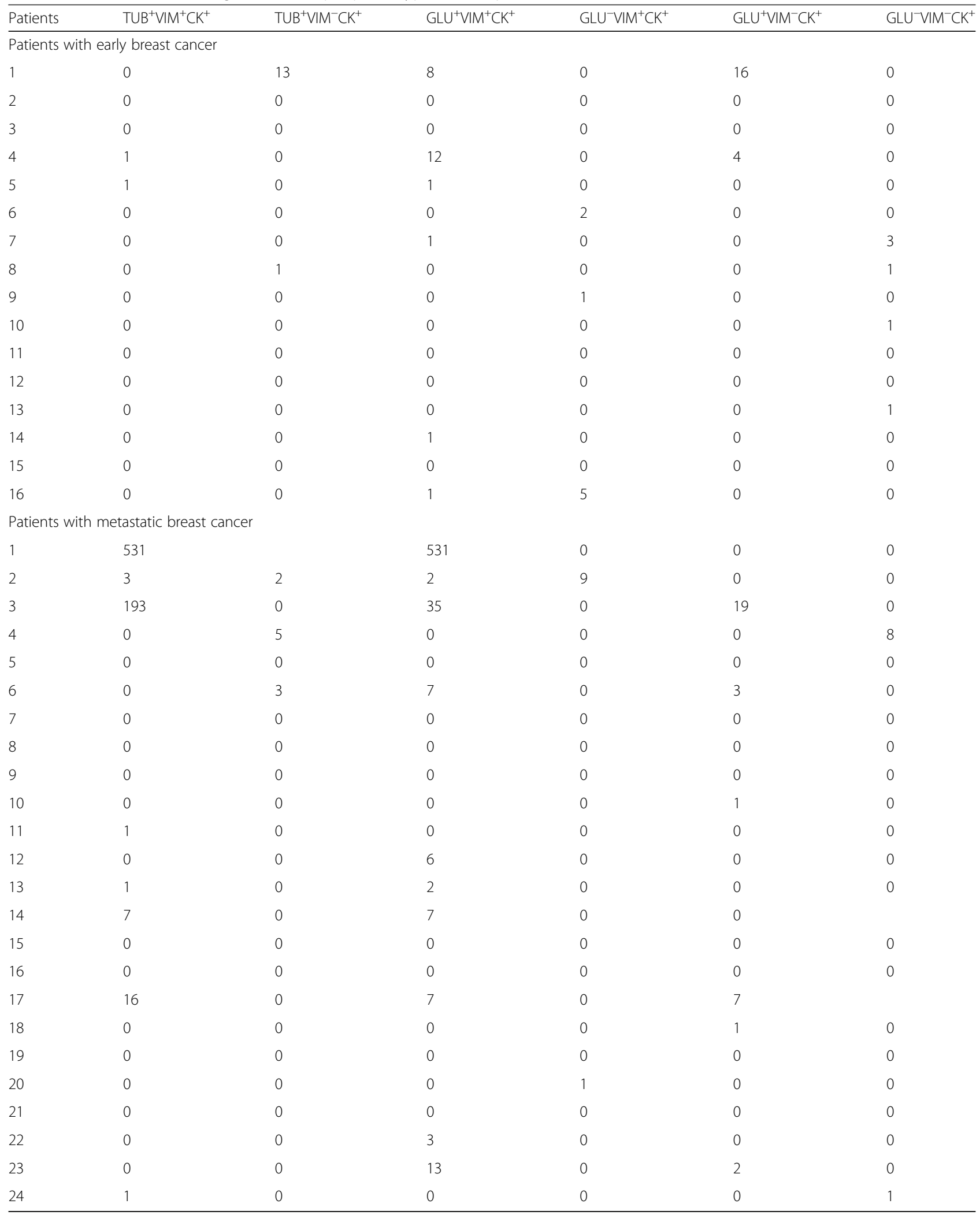

Abbreviations: CK Cytokeratin, TUB a-Tubulin, GLU Detyrosinated a-tubulin, VIM Vimentin 

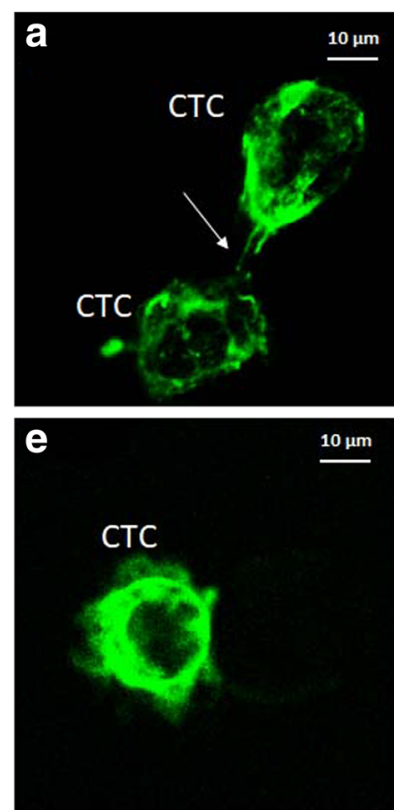

CK
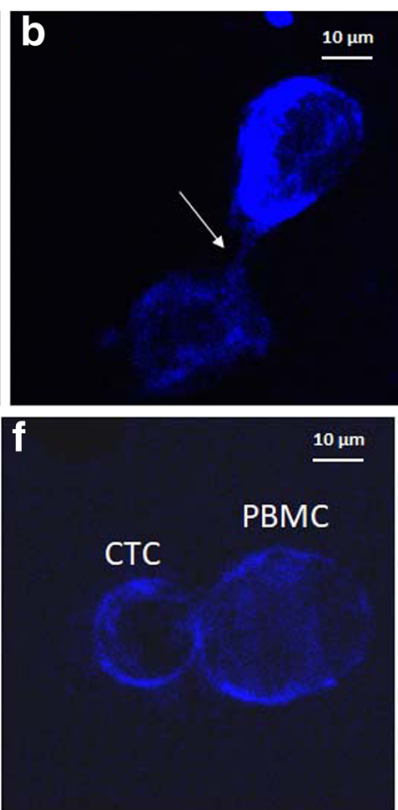

GLU-Tubulin
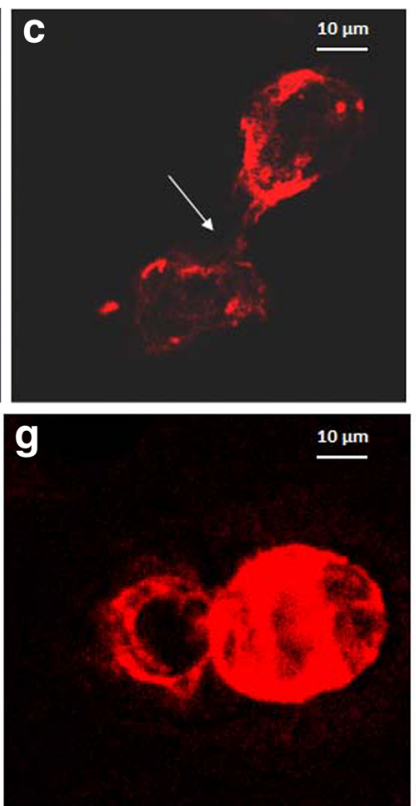

Vimentin

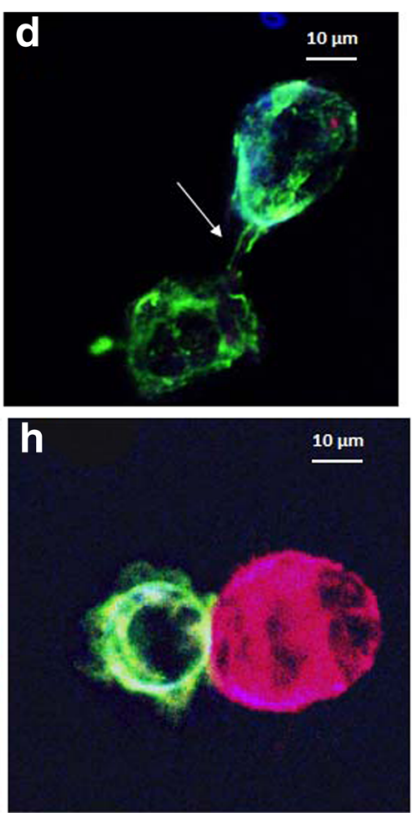

Overlay

Fig. 3 Expression of cytokeratin (CK), vimentin (VIM), and detyrosinated a-tubulin (GLU) in patients' circulating tumor cells (CTCs). Patients' samples were stained with pancytokeratin (A45-B/B3, green), detyrosinated tubulin (blue), and vimentin antibodies (red) and 4',6-diamidino-2-phenylindole (DAPI, not shown). a-d Representative confocal laser scanning micrographs of patients' CTCs (×60) stained with pancytokeratin (A45-B/B3), vimentin, and GLU antibodies. Intercellular connections through cytoskeletal bridges (white arrows) were observed between CTCs. These microtentacles were supported by GLU, VIM, and CK. e-h CK, VIM, and GLU expression on a patient's CTC (×60), which is in contact with a peripheral blood mononuclear cell from a patient sample

(Fig. 4Ia). In addition, the CK/TUB ratio was progressively statistically reduced $(p=0.003)$ (Fig. 4Id). Similarly, the intensity of GLU expression in CTCs was statistically increased $(p=0.002)$ between baseline and the time of relapse (Fig. 4Ib). The ratio CK/GLU was not significantly altered $(p=0.076)$ (Fig. 4Ie). Finally, there was also a statistical increase in VIM expression in CTCs $(p=0.011)$ when the patient's BC became metastatic (Fig. 4Ic). The CK/VIM ratio was also statistically decreased $(p=0.01)$, between the first and the second sample draws (Fig. 4If).

\section{CTC phenotypic profile and clinical outcome}

Although this study was a small pilot study and the results regarding clinical outcome are only exploratory, we analyzed the available clinical data from 22 of 24 patients with metastatic BC enrolled in this study. After a median follow-up of 8 months (range, 0-21), six patients $(25 \%)$ had died. Three of them presented with overt metastasis at the time of initial diagnosis, whereas the rest presented with early BC. Patients who died during the follow-up harbored more CTCs (mean, 15; median, 9.5; range, 0-54) than survivors (mean, 2.31; median, 1; range, 0-15); however, survival analysis for total CTCs per patient (Cox regression $p=0.142$, Kaplan-Meier $p=0.124$ ) did not show statistical differences in patient outcomes. On the other hand, survival analysis regarding distinct phenotypes revealed that median PFS was 3.0 months for the patients with detectable $\mathrm{GLU}^{+} \mathrm{VIM}^{+} \mathrm{CK}^{+}$-expressing CTCs compared with 7.5 months for patients who did not have detectable CTCs with this phenotype $(p=0.004)$ (Fig. 4IIa). Similarly, patients with detectable $\mathrm{GLU}^{-} \mathrm{VIM}^{+} \mathrm{CK}^{+}$-expressing CTCs had a median PFS of 1.0 month compared with 7.0 months for patients who did not have detectable CTCs with this phenotype ( $p=0.007)$ (Fig. 4IIb).

Finally, the ORR was significantly lower in patients with $\mathrm{TUB}^{+} \mathrm{VIM}^{+} \mathrm{CK}^{+}$-expressing CTCs compared with patients without CTCs bearing this phenotype $(p=0.046)$. Moreover, the ORR was significantly lower in patients with metastatic disease who had CTCs with high numbers of microtentacles (5 of 16 patients with $\left.\mathrm{CK}^{+}\right)(p=0.019)$. The criteria for the evaluation of ORR were according to RECIST 1.1: tumor size, lymph node status, lesion number, and so forth [32].

\section{Discussion}

It is widely accepted that although CTCs hold a crucial role in the metastatic process, the changes occurring during disease evolution on these cells are not fully characterized yet. CTCs hold significant prognostic value for patients with both early and metastatic BC [33-35]. It is also well known that microtentacles are increased in 


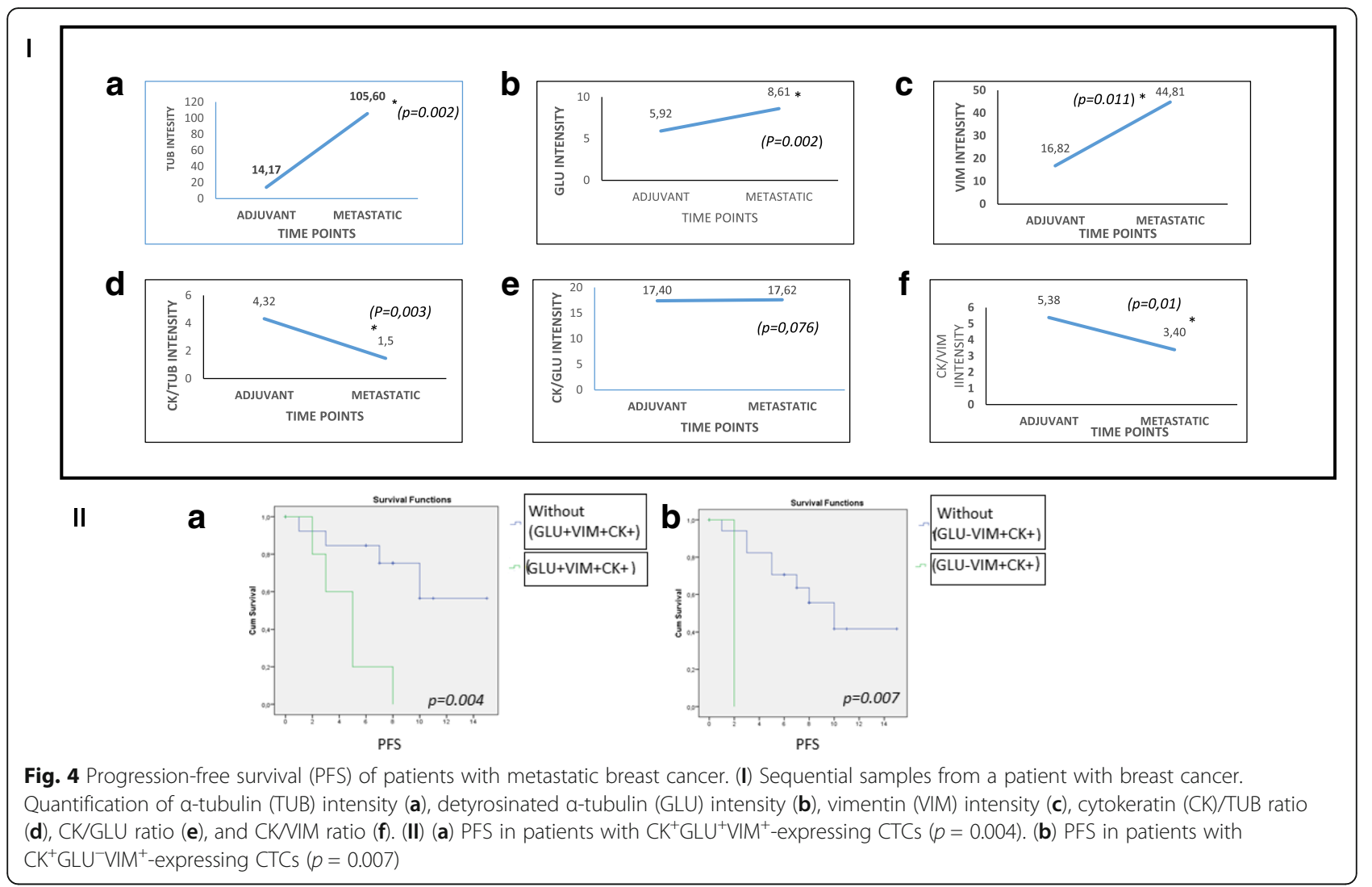

aggressive $\mathrm{BC}$ cells compared with less invasive phenotypes [19]. Microtentacles are supported by TUB, GLU, and VIM $[19,20]$. In the current study, we investigated the presence of those filamentous protrusions in CTCs isolated from early and metastatic patients with $\mathrm{BC}$. Moreover, the expression of the implicated molecules was quantified, and their association with the patients' clinical outcomes was assessed.

Our experiments revealed that microtentacles supported by TUB could be detected in patients early $\mathrm{BC}$ but mainly in those with metastatic BC. Interestingly, patients with increased numbers of microtentacle-presenting CTCs experienced a significantly lower ORR than patients with a low number of microtentacles $(p=0.019)$, suggesting that their tumors were more resistant to treatment. Furthermore, the results of the current study demonstrated that CTCs could contact each other (Figs. 1 and 3, white arrows) with filamentous protrusions supported by TUB, VIM, and GLU. These protrusions were also observed to connect CTCs with blood cells; however, in such junctions, only TUB and VIM were present, whereas CK expression was limited (Figs. 1 and 3). These findings are in agreement with previous observations in two other studies in which researchers reported that CTCs could be accompanied in the vessels by blood cells (giant macrophages) that seem to be associated with an unfavorable clinical outcome [36, 37]. Therefore, our results could potentially explain how CTCs may travel in the bloodstream next to blood cells.

In our quantification of the ratios CK/TUB, CK/GLU, and CK/VIM in three representative subtypes of $B C$ (MCF7 $\left[\mathrm{HR}^{+}\right]$, SKBR3 [HER2 $\left.{ }^{+}\right]$, and MDA-MB-231 [basal-like]), we observed that these ratios were statistically increased in MCF7 compared with SKBR3 and MDA-MB-231 cells. This suggests that they can be used as distinct markers to characterize less aggressive tumor cells, such as the $\mathrm{HR}^{+}$subtype from more invasive phenotypes. In addition, microtentacles were observed mostly in MDA-MB-231 cells (Additional file 1: Figure S1). These findings support previous studies in that basal-like cell lines have increased numbers of microtentacles [38]. Furthermore, MDA-MB-231 cells have significantly higher levels of VIM intensity $(28.87 \pm 3.7)$ than other cell lines (Additional file 2: Figure S2, Table 2), in accordance with previously published data [39].

Characterization of CTCs on the basis of these markers clearly indicated that CK/TUB and TUB intensity were statistically different in early $\mathrm{BC}$ compared with the metastatic setting (Table 2), implying that during disease evolution, the level of TUB increases relative to cytokeratin intensity. This observation could be a 
useful tool for the characterization of CTCs with more aggressive features, mostly in patients with early BC, where the cells are very heterogeneous [12]. The analysis of sequential samples from a patient with $\mathrm{BC}$ during the early and metastatic stages of the disease confirmed the previous observations. Indeed, during the course of the disease, the expression of TUB was significantly increased (Fig. 4a), whereas the CK/TUB ratio was decreased (Fig. 4d). These results strongly suggest that follow-up samples regarding TUB expression in CTCs could potentially give useful information about disease relapse before the appearance of clinical and laboratory findings of overt metastasis.

VIM intensity was also statistically increased in the basal-like cell line MDA-MB-231 compared with $\mathrm{HR}^{+}$ MCF7 cells (Table 2). Consequently, the ratio of CK/ VIM was also decreased in the aggressive cell line compared with $\mathrm{HR}^{+}$cells (Table 2). These results imply that VIM is also characteristic of more aggressive phenotypes, in accordance with previous studies [39]. These observations were confirmed in patients' samples, indicating that VIM intensity was statistically increased in metastatic $(p=0.0001)$ compared with early disease, whereas the CK/VIM ratio was significantly decreased $(p=0.007)$ in patients with advanced BC (Table 2).

Furthermore, although the CK/GLU ratio did not reach statistical significance between early and metastatic disease (Table 2), the intensity of GLU was significantly higher $(p=0.029)$ in patients with metastatic BC than in those with early BC (Table 2). These findings strongly suggest that GLU can also be a marker characterizing invasive subpopulations. In accordance with this, the presence of the $\mathrm{CK}^{+} \mathrm{GLU}^{+} \mathrm{VIM}^{+}$phenotype in patients' blood was associated with worse PFS $(p=0.004)$, suggesting that both markers (GLU and VIM) could represent poor prognosis factors when coexpressed in patients' CTCs. Interestingly, the total number of CTCs did not correlate with prognosis in patients with metastatic $\mathrm{BC}$, implying that the characterization of distinct phenotypes is critical for disease outcome, as we have previously shown [16]. This assumption is in line with previous studies regarding GLU expression in primary tumors [25]. However, this is a pilot study with a small number of patients; therefore, our results are only exploratory. A larger study with an increased number of patients is needed to confirm our observations.

It was also interesting that Spearman's correlation analysis revealed a correlation between CK/TUB and CK/ GLU ratios $(p=0.005)$ in CTCs. In addition, CK/GLU ratio was also significantly correlated to CK/VIM ratio $(p=0.011)$, implying that all these markers can be used concomitantly to underline an aggressive signature of CTCs in patients with BC. Finally, it is noteworthy that all these molecules were present in the junctions among
CTCs, mostly in patients with CTC clusters, and it is of interest that these patients have a 50 -fold increased risk of relapse [40].

\section{Conclusions}

Microtentacles observed in CTCs isolated from patients with $\mathrm{BC}$ participate in the communication among CTCs and the interaction between CTCs and blood cells. The proteins that support these protrusions (TUB, VIM, and GLU) potentially represent markers for the identification of CTCs with a more aggressive phenotype in patients with BC; however, a study with a larger group of patients is necessary to further confirm the clinical relevance of these findings.

\section{Additional files}

\begin{abstract}
Additional file 1: Figure S1. Expression of cytokeratin, vimentin, and a-tubulin on MCF7, SKBR3, and MDA-MB 231 cells spiked in normal blood and isolated with the ISET system. Representative confocal laser scanning micrographs of MCF7 $(\times 60)$, SKBR3 $(\times 40)$, and MDA-MB 231 $(\times 40)$ cells, triple-stained with pancytokeratin (A45-B/B3), vimentin, and a-tubulin antibodies. (JPG $117 \mathrm{~kb}$ )
\end{abstract}

Additional file 2: Figure S2. Single CTC distribution regarding TUB, VIM and GLU intensity. TUB expression in CTCs obtained from patients with (a) early and (b) metastatic breast cancer. Each dot represents the intensity of one CTC. GLU expression in CTCs obtained from patients with (c) early and (d) metastatic breast cancer. Each dot represents the intensity of one CTC. VIM expression in CTCs obtained from patients with (e) early and (f) metastatic breast cancer. Each dot represents the intensity of one CTC. (JPG $122 \mathrm{~kb}$ )

Additional file 3: Single CTC distribution regarding CKTUB, CKNIM, and CKVGLU ratios. CKJTUB ratio in CTCs obtained from patients with (a) early and (b) metastatic breast cancer. Each dot represents the intensity of one CTC. CK GLU ratio in CTCs obtained from patients with (c) early and (d) metastatic breast cancer. Each dot represents the intensity of one CTC. CKVIM ratio in CTCs obtained from patients with (e) early and (f) metastatic breast cancer. Each dot represents the intensity of one CTC. (JPG $130 \mathrm{~kb}$ )

\section{Abbreviations}

CTC: Circulating tumor cell; EDTA: Ethylenediaminetetraacetic acid; EMT: Epithelial-to-mesenchymal transition; ER: Estrogen receptor; GLU: Detyrosinated a-tubulin; HER: Human epidermal growth factor receptor 2; HR: Hormone receptor; IgG1: Immunoglobulin G1; ORR: Objective response rate; OS: Overall survival; PFS: Progression-free survival; PR: Progesterone receptor; RT: Room temperature; TUB: a-Tubulin; VIM: Vimentin

\section{Acknowledgements}

The authors acknowledge the partial support of this work by the Hellenic Oncology Research Group (HORG).

\section{Availability of data and materials}

The datasets used and/or analyzed during the current study are available from the corresponding author on reasonable request.

\section{Authors' contributions}

GK participated in the design, coordination and supervision of the study and in the preparation of the manuscript. DA performed staining experiments and ISET isolations. NZ performed immunofluorescence experiments. CS provided general support and participated in study design and manuscript preparation. VG provided general support, participated in study design, and provided the clinical samples. SSM participated in study design and manuscript preparation. All authors read and approved the final manuscript. 


\section{Ethics approval and consent to participate}

The protocol was approved by the ethics and scientific committees of our institution (D. Georgopoulos, I. Galanakis, I. Papadakis, H. Athanasakis, E. Kabitakis, M. Venihaki, A. Andreou, M. Grammatopouloou, M. Tabakaki), and all patients and healthy blood donors gave their informed consent to participate in the study.

\section{Consent for publication}

Our study does not contain any individual person's data.

\section{Competing interests}

The authors declare that they have no competing interests.

\section{Publisher's Note}

Springer Nature remains neutral with regard to jurisdictional claims in published maps and institutional affiliations.

\section{Author details}

'Laboratory of Tumor Cell Biology, School of Medicine, University of Crete, Heraklion, Greece. ²Department of Biochemistry, University of Crete, Greece Medical School, Heraklion, Greece. ${ }^{3}$ Department of Physiology, Marlene and Stewart Greenebaum Comprehensive Cancer Center, University of Maryland School of Medicine, 655 W. Baltimore Street, Baltimore, MD, USA.

\section{Received: 25 September 2017 Accepted: 25 May 2018}

\section{Published online: 05 July 2018}

\section{References}

1. Braun S, Harbeck N. Molecular markers of metastasis in breast cancer: current understanding and prospects for novel diagnosis and prevention. Expert Rev Mol Med. 2001;3(22):1-14.

2. Pantel K, Muller V, Auer M, Nusser N, Harbeck N, Braun S. Detection and clinical implications of early systemic tumor cell dissemination in breast cancer. Clin Cancer Res. 2003:9(17):6326-34.

3. Kallergi G, Papadaki MA, Politaki E, Mavroudis D, Georgoulias V, Agelaki S Epithelial to mesenchymal transition markers expressed in circulating tumour cells of early and metastatic breast cancer patients. Breast Cancer Res. 2011;13(3):R59.

4. Papadaki MA, Kallergi G, Zafeiriou Z, Manouras L, Theodoropoulos PA Mavroudis D, Georgoulias V, Agelaki S. Co-expression of putative stemness and epithelial-to-mesenchymal transition markers on single circulating tumour cells from patients with early and metastatic breast cancer. BMC Cancer. 2014:14:651.

5. Aktas B, Tewes M, Fehm T, Hauch S, Kimmig R, Kasimir-Bauer S. Stem cell and epithelial-mesenchymal transition markers are frequently overexpressed in circulating tumor cells of metastatic breast cancer patients. Breast Cancer Res. 2009:11(4):R46.

6. Bozionellou V, Mavroudis D, Perraki M, Papadopoulos S, Apostolaki S, Stathopoulos E, Stathopoulou A, Lianidou E, Georgoulias V. Trastuzumab administration can effectively target chemotherapy-resistant cytokeratin-19 messenger RNA-positive tumor cells in the peripheral blood and bone marrow of patients with breast cancer. Clin Cancer Res. 2004:10(24):8185-94.

7. Fehm T, Sagalowsky A, Clifford E, Beitsch P, Saboorian H, Euhus D, Meng S, Morrison L, Tucker T, Lane N, et al. Cytogenetic evidence that circulating epithelial cells in patients with carcinoma are malignant. Clin Cancer Res. 2002:8(7):2073-84

8. Hodgkinson CL, Morrow CJ, Li Y, Metcalf RL, Rothwell DG, Trapani F, Polanski R, Burt DJ, Simpson KL, Morris K, et al. Tumorigenicity and genetic profiling of circulating tumor cells in small-cell lung cancer. Nat Med. 2014; 20(8):897-903.

9. Meng S, Tripathy D, Frenkel EP, Shete S, Naftalis EZ, Huth JF, Beitsch PD, Leitch M, Hoover S, Euhus D, et al. Circulating tumor cells in patients with breast cancer dormancy. Clin Cancer Res. 2004;10(24):8152-62.

10. Kallergi G, Konstantinidis G, Markomanolaki H, Papadaki MA, Mavroudis D, Stournaras C, Georgoulias V, Agelaki S. Apoptotic circulating tumor cells in early and metastatic breast cancer patients. Mol Cancer Ther 2013;12(9):1886-95.

11. Spiliotaki M, Mavroudis D, Kapranou K, Markomanolaki H, Kallergi G, Koinis F, Kalbakis K, Georgoulias V, Agelaki S. Evaluation of proliferation and apoptosis markers in circulating tumor cells of women with early breast cancer who are candidates for tumor dormancy. Breast Cancer Res. 2014; 16(6):485.

12. Klein CA, Blankenstein TJ, Schmidt-Kittler O, Petronio M, Polzer B, Stoecklein $\mathrm{NH}$, Riethmuller G. Genetic heterogeneity of single disseminated tumour cells in minimal residual cancer. Lancet. 2002;360(9334):683-9.

13. Kallergi G, Mavroudis D, Georgoulias V, Stournaras C. Phosphorylation of FAK, PI-3K, and impaired actin organization in CK-positive micrometastatic breast cancer cells. Mol Med. 2007;13(1-2):79-88.

14. Kallergi G, Agelaki S, Kalykaki A, Stournaras C, Mavroudis D, Georgoulias V. Phosphorylated EGFR and PI3KJAkt signaling kinases are expressed in circulating tumor cells of breast cancer patients. Breast Cancer Res. 2008; 10(5):R80

15. Agelaki S, Dragolia M, Markonanolaki H, Alkahtani S, Stournaras C, Georgoulias V, Kallergi G. Phenotypic characterization of circulating tumor cells in triple negative breast cancer patients. Oncotarget. 2017; 8(3):5309-22

16. Kallergi G, Agelaki S, Papadaki MA, Nasias D, Matikas A, Mavroudis D, Georgoulias V. Expression of truncated human epidermal growth factor receptor 2 on circulating tumor cells of breast cancer patients. Breast Cancer Res. 2015;17:113

17. Kalykaki A, Agelaki S, Kallergi G, Xyrafas A, Mavroudis D, Georgoulias V. Elimination of EGFR-expressing circulating tumor cells in patients with metastatic breast cancer treated with gefitinib. Cancer Chemother Pharmacol. 2014;73(4):685-93.

18. Georgoulias V, Bozionelou V, Agelaki S, Perraki M, Apostolaki S, Kallergi G, Kalbakis K, Xyrafas A, Mavroudis D. Trastuzumab decreases the incidence of clinical relapses in patients with early breast cancer presenting chemotherapy-resistant CK-19 mRNA-positive circulating tumor cells: results of a randomized phase II study. Ann Oncol. 2012;23(7):1744-50.

19. Whipple RA, Balzer EM, Cho EH, Matrone MA, Yoon JR, Martin SS, Vimentin filaments support extension of tubulin-based microtentacles in detached breast tumor cells. Cancer Res. 2008;68(14):5678-88.

20. Whipple RA, Matrone MA, Cho EH, Balzer EM, Vitolo MI, Yoon JR, loffe OB, Tuttle KC, Yang J, Martin SS. Epithelial-to-mesenchymal transition promotes tubulin detyrosination and microtentacles that enhance endothelial engagement. Cancer Res. 2010;70(20):8127-37.

21. Balzer EM, Whipple RA, Thompson K, Boggs AE, Slovic J, Cho EH, Matrone MA, Yoneda T, Mueller SC, Martin SS. C-Src differentially regulates the functions of microtentacles and invadopodia. Oncogene. 2010;29(48):6402-8.

22. Charpentier MS, Whipple RA, Vitolo Ml, Boggs AE, Slovic J, Thompson KN, Bhandary L, Martin SS. Curcumin targets breast cancer stem-like cells with microtentacles that persist in mammospheres and promote reattachment. Cancer Res. 2014;74(4):1250-60.

23. Matrone MA, Whipple RA, Thompson $\mathrm{K}$, Cho EH, Vitolo MI, Balzer EM, Yoon JR, loffe OB, Tuttle KC, Tan M, et al. Metastatic breast tumors express increased tau, which promotes microtentacle formation and the reattachment of detached breast tumor cells. Oncogene. 2010;29(22):3217-27.

24. Perry NA, Vitolo MI, Martin SS, Kontrogianni-Konstantopoulos A. Loss of the obscurin-RhoGEF downregulates RhoA signaling and increases microtentacle formation and attachment of breast epithelial cells. Oncotarget. 2014:5(18):8558-68.

25. Mialhe A, Lafanechere L, Treilleux I, Peloux N, Dumontet C, Bremond A, Panh MH, Payan R, Wehland J, Margolis RL, et al. Tubulin detyrosination is a frequent occurrence in breast cancers of poor prognosis. Cancer Res. 2001; 61(13):5024-7.

26. Hekimian K, Meisezahl S, Trompelt K, Rabenstein C, Pachmann K. Epithelial cell dissemination and readhesion: analysis of factors contributing to metastasis formation in breast cancer. ISRN Oncol. 2012:2012:601810.

27. Karagiannis GS, Pastoriza JM, Wang Y, Harney AS, Entenberg D, Pignatelli J, Sharma VP, Xue EA, Cheng E, D'Alfonso TM, et al. Neoadjuvant chemotherapy induces breast cancer metastasis through a TMEM-mediated mechanism. Sci Transl Med. 2017:9(397):eaan0026.

28. Balzer EM, Whipple RA, Cho EH, Matrone MA, Martin SS. Antimitotic chemotherapeutics promote adhesive responses in detached and circulating tumor cells. Breast Cancer Res Treat. 2010;121(1):65-78.

29. Yoon JR, Whipple RA, Balzer EM, Cho EH, Matrone MA, Peckham M, Martin SS. Local anesthetics inhibit kinesin motility and microtentacle protrusions in human epithelial and breast tumor cells. Breast Cancer Res Treat. 2011: 129(3):691-701.

30. Cristofanilli M, Budd GT, Ellis MJ, Stopeck A, Matera J, Miller MC, Reuben JM, Doyle GV, Allard WJ, Terstappen LW, et al. Circulating tumor cells, disease 
progression, and survival in metastatic breast cancer. N Engl J Med. 2004; 351(8):781-91.

31. Kallergi G, Politaki E, Alkahtani S, Stournaras C, Georgoulias V. Evaluation of isolation methods for circulating tumor cells (CTCS). Cell Physiol Biochem. 2016;40(3-4):411-9.

32. Eisenhauer EA, Therasse P, Bogaerts J, Schwartz LH, Sargent D, Ford R, Dancey J, Arbuck S, Gwyther S, Mooney M, et al. New response evaluation criteria in solid tumours: revised RECIST guideline (version 1.1). Eur J Cancer. 2009;45(2):228-47.

33. Cristofanilli M, Hayes DF, Budd GT, Ellis MJ, Stopeck A, Reuben JM, Doyle GV, Matera J, Allard WJ, Miller MC, et al. Circulating tumor cells: a novel prognostic factor for newly diagnosed metastatic breast cancer. J Clin Oncol. 2005;23(7):1420-30

34. Stathopoulou A, Vlachonikolis I, Mavroudis D, Perraki M, Kouroussis C, Apostolaki S, Malamos N, Kakolyris S, Kotsakis A, Xenidis N, et al. Molecular detection of cytokeratin-19-positive cells in the peripheral blood of patients with operable breast cancer: evaluation of their prognostic significance. J Clin Oncol. 2002;20(16):3404-12.

35. Xenidis N, Perraki M, Kafousi M, Apostolaki S, Bolonaki I, Stathopoulou A, Kalbakis K, Androulakis N, Kouroussis C, Pallis T, et al. Predictive and prognostic value of peripheral blood cytokeratin-19 mRNA-positive cells detected by real-time polymerase chain reaction in node-negative breast cancer patients. J Clin Oncol. 2006;24(23):3756-62.

36. Adams DL, Martin SS, Alpaugh RK, Charpentier M, Tsai S, Bergan RC, Ogden IM, Catalona W, Chumsri S, Tang CM, et al. Circulating giant macrophages as a potential biomarker of solid tumors. Proc Natl Acad Sci U S A. 2014; 111(9):3514-9.

37. Adams DL, Adams DK, Alpaugh RK, Cristofanilli M, Martin SS, Chumsri S, Tang CM, Marks JR. Circulating cancer-associated macrophage-like cells differentiate malignant breast Cancer and benign breast conditions. Cancer Epidemiol Biomarkers Prev. 2016;25(7):1037-42.

38. Boggs AE, Vitolo MI, Whipple RA, Charpentier MS, Goloubeva OG, loffe OB, Tuttle KC, Slovic J, Lu Y, Mills GB, et al. Alpha-tubulin acetylation elevated in metastatic and basal-like breast cancer cells promotes microtentacle formation, adhesion, and invasive migration. Cancer Res. 2015;75(1):203-15.

39. Flodrova D, Toporova L, Macejova D, Lastovickova M, Brtko J, Bobalova J. A comparative study of protein patterns of human estrogen receptor positive (MCF-7) and negative (MDA-MB-231) breast cancer cell lines. Gen Physiol Biophys. 2016;35(3):387-92.

40. Aceto N, Bardia A, Miyamoto DT, Donaldson MC, Wittner BS, Spencer JA, Yu M, Pely A, Engstrom A, Zhu H, et al. Circulating tumor cell clusters are oligoclonal precursors of breast cancer metastasis. Cell. 2014;158(5):1110-22.

Ready to submit your research? Choose BMC and benefit from:

- fast, convenient online submission

- thorough peer review by experienced researchers in your field

- rapid publication on acceptance

- support for research data, including large and complex data types

- gold Open Access which fosters wider collaboration and increased citations - maximum visibility for your research: over $100 \mathrm{M}$ website views per year

At BMC, research is always in progress.

Learn more biomedcentral.com/submissions 